Virginia Commonwealth University vCU Scholars Compass

2012

\title{
Evaluation of a Revised Curriculum: A Four-Year Qualitative Study of Student Perceptions
}

Sharon K. Lanning

Virginia Commonwealth University, sklanning@vcu.edu

Angela P. Wetzel

Virginia Commonwealth University, apwetzel@vcu.edu

Meredith B. Baines

Virginia Commonwealth University, mbbaines@vcu.edu

B. Ellen Byrne

Virginia Commonwealth University, bebyrne@vcu.edu

Follow this and additional works at: http://scholarscompass.vcu.edu/peri_pubs

8 Part of the Periodontics and Periodontology Commons

Reprinted by permission of Journal of Dental Education, Volume 76, 10 (October 2012). Copyright 2012 by the American Dental Education Association.

\section{Downloaded from}

http://scholarscompass.vcu.edu/peri_pubs/2

This Article is brought to you for free and open access by the Dept. of Periodontics at VCU Scholars Compass. It has been accepted for inclusion in Periodontics Publications by an authorized administrator of VCU Scholars Compass. For more information, please contact libcompass@vcu.edu. 


\title{
Evaluation of a Revised Curriculum: A Four-Year Qualitative Study of Student Perceptions
}

\author{
Sharon K. Lanning, D.D.S.; Angela P. Wetzel, Ph.D.; Meredith B. Baines, M.Ed.; \\ B. Ellen Byrne, D.D.S., Ph.D.
}

Abstract: Following curricular revisions at the Virginia Commonwealth University School of Dentistry, this longitudinal study was designed to determine students' perceptions of their educational experience in the revised curriculum. A SWOT (Strengths, Weaknesses, Opportunities, and Threats) open-ended response questionnaire was administered to students in the class of 2011 ( $\mathrm{N}=89$ ) in January of each academic year, 2008 through 2011, followed by focus groups three months prior to graduation. The overall response rate for the questionnaire was 69 percent, and a total of fourteen students participated in four focus groups. Cumulatively, 1,382 responses (SWOT=984 and focus groups=398) were qualitatively analyzed, and five themes emerged: 1 ) early clinical experiences led to a perceived readiness for direct patient care; 2) the pace and organization of the revised condensed preclinical curriculum were perceived as hectic yet were appreciated as necessary preparation for patient care; 3) most faculty members were seen as committed to student learning, but a few were reported to have poor teaching skills and attitudes when interacting with students; 4) a perceived lack of patients led to fewer clinical experiences and a decrease in student confidence; and 5) some curricular content was seen to be redundant and irrelevant to future practice. The results indicate that the students were satisfied with aspects of their educational experience, suggesting the revised curriculum's preliminary success in meeting its goals of earlier patient care, a condensed preclinical curriculum, and a student-friendly environment. As the curriculum is adapted in response to student feedback, ongoing evaluation is necessary and should be complemented by other evaluation indicators such as faculty perceptions and student learning outcomes.

Dr. Lanning is Associate Professor, Department of Periodontics, Virginia Commonwealth University School of Dentistry; Dr. Wetzel is Director of Assessment, Department of Foundations of Education, Virginia Commonwealth University School of Education; Ms. Baines is Director of Curriculum Advancement, Office of Academic Affairs, Virginia Commonwealth University School of Dentistry; and Dr. Byrne is Senior Associate Dean, Office of Academic Affairs, Virginia Commonwealth University School of Dentistry. Direct correspondence and requests for reprints to Dr. Sharon K. Lanning, School of Dentistry, Virginia Commonwealth University, 521 North 11th Street, Richmond, VA 23298; 804-828-7951 phone; 804-828-0657 fax; sklanning@vcu.edu.

This article is one in a series of invited contributions by members of the dental education community that have been commissioned by the ADEA Commission on Change and Innovation in Dental Education (ADEA CCI) to address the environment surrounding dental education and affecting the need for, or process of, curricular change. This article was written at the request of the ADEA CCI but does not necessarily reflect the views of ADEA, the ADEA CCI, or individual members of the CCI. The perspectives communicated here are those of the authors.

Keywords: dental education, dental students, dental faculty, curriculum, assessment, clinical education, qualitative research

Submitted for publication 9/12/11; accepted 12/30/11

I n its 1995 call for reform of dental education entitled Dental Education at the Crossroads: Challenges and Change, the Institute of Medicine (IOM) of the National Academy of Sciences noted that current dental curricula contained redundant content and often isolated elements within disciplinary silos. ${ }^{1}$ Further, the report argued that dental curricula did not reflect contemporary dental practice, prepare students for emerging advances in dentistry, or promote the link between oral and systemic health. In
2005, twenty years after the IOM report, it was noted that little progress had been seen in dental education, ${ }^{2}$ and commissioned articles of the American Dental Education Association Commission on Change and Innovation in Dental Education (ADEA CCI) continued to characterize dental school curricula as congested, irrelevant, and disjointed and lacking effective integration between the basic and clinical sciences. ${ }^{2-4}$ An overloaded curriculum promotes "student gaming" as a means of survival instead of 
developing skills thought to be critical for future practice.

Curricular revisions at the Virginia Commonwealth University School of Dentistry (VCU SoD) have been undertaken for largely local reasons; however, the challenges we face are not unique and reflect many of the key issues in the IOM report and ADEA CCI articles. The main goals of the VCU SoD curricular revisions were based on ADEA CCI best practices and other recommendations in the literature: 1) introduce earlier patient care, 2) condense the preclinical curriculum, and 3) develop a student-friendly and mutually respectful school environment. ${ }^{1-7}$ These goals are interrelated and grounded in the idea that a student-friendly learning environment would be a result of introducing earlier patient care experiences by streamlining the existing preclinical curriculum and delivering its essential components in a shorter time frame. With a foundation in the literature on best practices, our experiences with implementing curricular change to address deficiencies can inform others in dental education and perhaps the larger health professions education communities.

In planning for the implementation of our curricular revisions, the first two years of the program (basic and clinical sciences) underwent a methodical and systematic review utilizing school-based curricular data, national dental curricula reports, and published data on national board exam content. Irrelevant content and redundant content were eliminated; biochemistry was made a predental prerequisite for admission; and existing content was restructured, leading to a six-credit hour reduction in basic science instruction. More specifically, the redundant content of our human genetics, periodontics, and pediatric dentistry courses was eliminated; all biochemistry topics except wound healing and carbohydrate metabolism were eliminated; and topics of reproductive, gastrointestinal, and genitourinal histology were eliminated. Clinical science instruction was streamlined by reorganizing content and moving four courses (Clinical Skills I and II and Periodontics I and II) forward by one year, introducing computerized dental simulation, and adding two courses to the existing clinical skills series. The clinical skills series accommodated content reorganized from the four courses that moved forward in the curriculum by one year and introduced clinical rotations in the second year. Three semesters of operative dentistry were condensed into two semesters without loss of credit hours or content.
Timely evaluation of these curricular changes by students, as major stakeholders, is critical to understanding their educational experience and helps to inform the faculty and administrators about the current status of the curriculum and necessary further enhancements. Therefore, the purpose of this study was to qualitatively capture student perceptions about their teaching and learning experience following curricular revision using an open-ended response SWOT (Strengths, Weaknesses, Opportunities, and Threats) questionnaire ${ }^{8}$ and focus groups.

\section{Methods}

With the approval of the Virginia Commonwealth University Institutional Review Board, students of the dental school class of $2011(\mathrm{~N}=89)$, who had experienced the entire revised curriculum, were invited by e-mail announcement (three separate times) during January of their first, second, third, and fourth years, 2008 through 2011, to complete the qualitative SWOT questionnaire. ${ }^{8}$ The students were advised of the purpose of the study and how data would be used to inform further curricular enhancements. Participation was voluntary. Students received a complimentary lunch for their participation. Responses were anonymous. Three months prior to graduation, the students were invited by e-mail announcement (three separate times) to participate in one of four focus groups with the goal of further discussion and clarification of students' perceived quality of the educational program guided by the qualitative survey results. Participation in the focus groups was voluntary, and students again received a complimentary lunch for participating. The students were advised that responses in the focus group were confidential to the group and that transcriptions would not include student identifiers or names.

The SWOT questionnaire was administered annually, in person, at a designated time independent of class. Students were given sixty minutes to complete the paper-based questionnaire in long hand. The SWOT questionnaire ${ }^{8}$ was selected for this study based on its previous use in health professions education to gather opinions about the quality of educational programs and recommendations for improvement. ${ }^{9,10}$ Students were asked to respond in writing to the following questions, basing their responses on their most recent curricular experiences:

1. What have been the strengths of your dental education so far? 
2. What have been weaknesses in your dental education so far?

3. What are the opportunities for improvement that would most dramatically enhance the quality of the dental education experience for you and for future students?

4. What are the threats to the quality of dental education that need to be addressed, so dental school remains attractive to college students making decisions about professional careers?

Based on preliminary analysis of the SWOT questionnaire data, a semi-structured discussion guide was developed to prompt focus group participants to reflect on their overall educational experience. The standardized questions in the discussion guide were specifically designed to solicit feedback that would aid in interpretation of the four years of SWOT data and to provide insight into the perspective that the completion of training offers. Prepared questions addressed students' perceived level of preparedness for entry into dental school clinics and practice as a general dentist, curricular content and organization, and the school's learning environment (Table 1). Extemporaneous follow-up questions were asked by the facilitator as needed to clarify comments and responses or to redirect off-topic conversation. One author (MBB) was selected to facilitate the focus groups based on her role in the school; since she had no association with student grades, assessment, or performance in didactic or clinical courses, it was anticipated that students would be open and comfortable sharing responses with her. Focus group discussions were approximately ninety minutes in duration and were audiorecorded and transcribed verbatim after each discussion.

The transcribed student responses from the paper-based SWOT questionnaire were deduced into meaningful units of text representing a single concept. Rather than using a predefined set of qualitative codes, code categories were allowed to emerge from the data. Individual units of text addressing similar concepts were sorted by the authors into groupings. The most frequently expressed concepts became the code categories (e.g., preclinical and clinical experi-

\section{Table 1. Questions on the semi-structured discussion guide used with focus groups in study}

1. SWOT data suggest that first- and second-year students feel prepared to enter clinical practice within our school clinics.

A. Thinking back to your first and second years, what prepared you the most to enter clinical practice within our clinics?

B. What could be enhanced or added to the curriculum to better prepare students to enter clinical practice within our clinics?

C. Did the majority of your clinical experiences in your second year involve direct patient care or assisting other students?

D. Were these meaningful experiences? Why or why not?

2. Based on your experiences overall within the curriculum, answer the following questions:

A. Has the curriculum prepared you to enter patient care as a general dentist?

B. Are there areas or disciplines in which you feel more prepared than others?

C. In what areas or disciplines do you feel least prepared?

D. What could be enhanced or added to the curriculum to better prepare you to enter independent practice?

E. Who will enter practice immediately after graduation? How many plan to enter a residency? What residency do you plan to enter?

3. SWOT data suggest that students feel faculty members were supportive and promoted a positive learning environment.

A. How did faculty members create a positive learning environment both within the classroom and clinic?

B. How did faculty members create a negative learning environment both within the classroom and clinic?

4. SWOT data suggest students feel that the pace of the curriculum, particularly during the first two years, is hectic.

A. What impact did this have on you?

B. How could the first two years be improved?

5. SWOT data suggest students feel there are redundancies in the curriculum.

A. Provide an example or two of redundancies.

B. Why do you feel redundancies in the curriculum occur?

C. Do you think redundancies are the result of poor communication between faculty members regarding students' prerequisite knowledge?

6. Regarding your clinical education:

A. What stands out as a positive experience in your clinical education?

B. What stands out as a negative experience in your clinical education? 
ence, curriculum, and faculty and teaching) that were further specified using subcategories (e.g., course names). The complete coding scheme was developed by three of the authors (SKL, APW, and BEB) and supplemented with a coding dictionary. ${ }^{11}$ The coding scheme and dictionary were tested through several rounds of practice coding with subsets of the data, and additional code categories were created or existing categories merged to reflect patterns in the data. From there, two authors (SKL and APW) independently coded a subset of the data to calculate intercoder reliability. With high agreement in application of the code scheme and dictionary (greater than 80 percent agreement for all categories), one of the authors (APW) coded the remainder of the data using NVivo qualitative software, version 8 (QSR International Inc., Cambridge, MA).

Response data from each of the four focus groups were stripped of student identifiers, combined into one set of focus group data, and coded using the study's coding scheme and dictionary. Two of the authors (MBB and SKL) independently coded a subset of the data to calculate intercoder reliability. With high agreement in application of the code scheme and dictionary (greater than 90 percent agreement for all categories), one of the authors (SKL) coded the remainder of the data. From the questionnaire and focus group data sets, overall key themes were identified from high frequency code categories. ${ }^{11-13}$

In total, 1,177 comments or units of data were collected from the SWOT questionnaire responses. The students provided 193 comments on opportunities and threats. The vast majority of these comments were redundant with strengths and weaknesses expressed by the same student, leaving only fifty comments considered true opportunities and threats. These fifty comments did not yield any discernible general themes and appeared to be all stand-alone or random comments. Thus, comments expressed as opportunities and threats were incorporated into our internal program review, but this study reports findings related only to strengths and weaknesses.

\section{Results}

The overall response rate on the SWOT questionnaire was 69 percent. Responses by year were as follows: first-year, 76 percent (68/89); second-year, 84 percent (76/90); third-year, 64 percent (57/89); and fourth-year, 51 percent (45/89). Of the 984 comments, the greatest number were provided in the second year, coinciding with the highest response rate year (Table 2). A total of fourteen students (16 percent) participated in four focus groups. These fourteen included ten men and four women, a variety of age groups (between twenty-six and thirty-five years of age), and an assortment of post-dental school career paths (such as solo and group practice, military, and specialty and general dentistry postgraduate programs). A total of 398 audible comments were received and transcribed into units of data (Table 3 ).

Based on frequently expressed comments from highest to lowest, the following five themes were identified: 1) preclinical laboratory and early clinical experiences led to a perceived readiness for direct patient care (34 percent); 2) the pace and organization of the revised condensed preclinical curriculum were perceived as hectic yet were appreciated as necessary preparation for patient care (19 percent); 3 ) most faculty members were seen as committed to student learning, but a few were reported to have poor teaching skills and attitudes when interacting with students (18 percent); 4) a perceived lack of patients led to fewer clinical experiences and a decrease in student confidence (12 percent); and 5) some curricular content was seen to be redundant and irrelevant to future practice ( 9 percent). None of the remaining comments fell into any of these categories and did not center on an additional cohesive theme.

Table 2. Distribution and total number of respondents' comments on SWOT questionnaire, by year

\begin{tabular}{|c|c|c|c|c|c|}
\hline Main Categories & $\begin{array}{l}\text { First Year, } 2008 \\
\qquad(\mathrm{~N}=68)\end{array}$ & $\begin{array}{l}\text { Second Year, } 2009 \\
\qquad(N=76)\end{array}$ & $\begin{array}{l}\text { Third Year, } 2010 \\
\qquad(N=57)\end{array}$ & $\begin{array}{l}\text { Fourth Year, } 2011 \\
\qquad(\mathrm{~N}=45)\end{array}$ & Total \\
\hline Preclinical and Clinical Experience & 63 & 218 & 105 & 71 & 457 \\
\hline Communication & 2 & 14 & 2 & 0 & 18 \\
\hline Curriculum & 102 & 172 & 20 & 5 & 299 \\
\hline Facilities & 1 & 15 & 2 & 0 & 18 \\
\hline Faculty and Teaching & 19 & 96 & 23 & 11 & 149 \\
\hline School Environment & 10 & 21 & 8 & 4 & 43 \\
\hline Total & 197 & 536 & 160 & 91 & 984 \\
\hline
\end{tabular}




\section{Earlier Patient Care}

Approximately 30 percent of the SWOT comments from students completing the survey in their first or second year concerned the preclinical laboratories and early clinical experiences, and nearly 75 percent of these comments reported strengths. Students perceived that the laboratories and clinical experiences fostered their readiness for direct patient care in the dental school clinics by enhancing their psychomotor skills and knowledge of clinical procedures and clinic operations. The following examples of student comments reflected this theme: "Getting into the preclinical labs and developing our hands-on skills and indirect vision from the start so we can feel more comfortable by the time we are with patients"; "Preclinical lab projects have done a good job preparing me for clinic"; "The largest strength of our recently revised curriculum is the amount of early hands-on training. These experiences have given us more opportunities to develop hand-eye/psychomotor skills than our peers in the years ahead of us"; "Being in the clinic during our second year has helped me get comfortable with the way things work before having to deal with patients"; and "I think it has really paid off entering the clinic [in the] first and second years. I feel comfortable in the clinic."

All fourth-year students participating in the focus groups confirmed the value of the preclinical laboratories and early clinical experiences. One hundred percent of the comments on this theme confirmed that the students found the early clinical experiences to be worthwhile, even though they acknowledged that most experiences at that level involved assisting more senior students rather than directly treating patients. The following comment is from a student who reflected on the benefit of patient contact while assisting a senior-level student: "There is nothing better than actually working with a patient, whether it's seeing how the clinics run or what a real tooth looks like or the patient interaction when the D4 [fourth-year] walks away and you're alone with a patient. You have to learn how to talk to the patient. You cannot replace the patient time that we got."

The most frequent deficiency identified by firstand second-year students through the SWOT survey in the areas of preclinical laboratories and early clinical experiences involved the perception of insufficient faculty coverage in preclinical laboratories. This point constituted 10 percent of comments and is illustrated by the following comments: "[There's] not enough faculty to meet time constraints on certain
Table 3. Distribution and total number of comments from fourth-year students in focus groups

\begin{tabular}{lc} 
Main Categories & $\begin{array}{c}\text { Fourth Year, 2011 } \\
(\mathrm{N}=14)\end{array}$ \\
\hline Preclinical and Clinical Experience & 143 \\
Curriculum & 133 \\
Faculty and Teaching & 122 \\
Total & 398 \\
\hline
\end{tabular}

projects. When faculty are unavailable to evaluate student work in a timely manner, it lowers the amount that can be accomplished in a given time period"; and "Lots of waiting time due to too few faculty to accommodate adequate time for evaluation/inspection of student work."

In the focus groups, the most frequently offered comments by fourth-year students on ways to improve the curriculum involved better implementation of the vertically integrated clinic system, more training on the school's electronic health care database, and establishing a fundamental treatment planning course for second-year students. The vertically integrated clinic model used in our predoctoral clinics consists of students from first through fourth years who engage in patient care, either solo or in pairs, as appropriate for their level of training and skill development. For example, a second-year student on clinical rotation through his or her assigned group dental practice may chair-side assist any third- or fourth-year student performing a complex restorative or prosthetic procedure. In regards to enhancing this system, the majority of fourth-year students thought a clearer definition of the role of the second-year students in the clinics might motivate them to assist with patient care. This is demonstrated by the following quote: "At the start of the semester there were always D2s [second-year students] wanting to help, and now I have to beg someone to help me. I offer to have them work on the patient ... all they want to do is sims [simulations]. I think helping out, assisting somebody in clinic, is a much more beneficial way to spend time than cutting a prep on a plastic tooth."

\section{Pace and Organization of Condensed Preclinical Curriculum}

Nearly 20 percent of the comments from students in their first and second years were related to the pacing and organization of the preclinical curriculum. Although students described individual courses as 
well organized, their comments highlighted concerns about course sequence and a general feeling of rushing to finish coursework in order to enter clinical practice earlier than previous dental school classes. Comments focused on the sometimes hectic pace of the curriculum due to a number of rigorous courses being scheduled simultaneously. Students commented that spreading these courses throughout the curriculum may help them to better master course content and ease frustration and anxiety. Examples include the following: "There needs to be a better balance between the D1 [first-year] first and second semesters. The course load for the first semester was way too light, and the second semester is too much. Possibly move one of the heavy science courses to first semester"; "Stress load in second semester is overwhelming; the classes should be spread out better between first and second semesters"; and "The largest weakness has been the sequencing of classes and the rate at which we've done both course and lab work to push us into clinics earlier."

In the focus groups with fourth-year students, 60 percent of the comments on this theme agreed that the pace of the curriculum during the first two years was hectic. However, with the perspective that hindsight can offer, the students acknowledged it was necessary to adequately prepare them for the third and fourth years, when patient care comprises the majority of their curricular time. For example, one student said, "If we did not move through the courses as we did, we would not have been prepared for our third year."

Twenty-three percent of the fourth-year student comments in focus groups related to the pace of the curriculum in the first two years and their perception of poor time management skills exhibited by the current second-year class. The fourth-year students indicated that the current second-year students were leaving preclinical laboratory sessions early to study and thus were not adequately using time allotted for instruction and faculty feedback. The fourth-years saw this practice as having a negative impact on their own clinical productivity since greater numbers of patients could be seen overall if faculty members were scheduled in the clinics instead. As stated by one fourth-year student, "I wouldn't have even thought that we had the option to leave [the preclinical laboratory] . . but I think if their [second-year students'] things aren't signed off, they shouldn't be allowed to go. Because they're in school, this is what they're here for. How much would we love for those faculty members to be downstairs with us and have [patient] appointments available?"

\section{Dental School Faculty}

Overall, 18 percent of the comments in the SWOT data related to faculty and teaching, with 40 percent of those describing strengths. The students perceived most of the faculty members to be knowledgeable, approachable, and committed to student learning as expressed by the following comments: "Dealing with the different faculty members in clinic and lab. This widens the horizon and introduces us to different ways of treatment"; "Faculty members are awesome! They want us to succeed and are willing to help us when necessary"; "Overall attitude of the faculty towards students is positive, respectful, and constructive"; and "Chance to meet different faculty (full-time, part-time, military background, private practice owner, etc.). Learning different philosophies and experiences."

The fourth-year students in the focus groups agreed that the faculty helped to create a positive learning environment, with 38 percent of the comments speaking to this theme. Examples included the following: "I think the faculty here is probably the school's greatest strength. They're extremely helpful. They seem very dedicated"; and "Comfortable, approachable faculty that would help if I had a question."

Nonetheless, the majority of student comments in both the SWOT data and focus groups centered on deficiencies related to some faculty members' perceived lack of teaching abilities and poor attitudes when interacting with students in the clinical environment. These deficiencies seemed to involve only a small group of faculty members, who were often identified by name. Comments included the following: "Faculty are boring and just read their slides"; "Our tests did not reflect what was covered in class. It was all memorization"; "Certain faculty members are difficult to work with and make clinic a burden instead of an enjoyable learning experience"; and "Faculty members are generally good, but one I've been in contact with does not hesitate to dress you down in front of your patient."

\section{Dental School Patients}

Overall, 12 percent of student comments captured in the SWOT questionnaire were related to a perceived lack of dental school patients. Comments on this theme surfaced in the second year of the program and became more frequent in years three and four. Thirty-one percent of students' comments during focus groups centered on their perceived 
readiness for entry-level practice. In clinical areas with a perceived ample supply of patients and numerous opportunities for clinical experiences, students reported confidence in their training and skill development during the focus group discussions. Students most frequently expressed confidence in their abilities related to operative dentistry and oral surgery. Conversely, they expressed a lack of confidence in the areas of fixed prosthodontics and endodontics, in which they felt they had an inadequate number of patient experiences. Students elaborated on potential reasons for a lack of dental school patients available to receive fixed prosthodontic or endodontic treatment. With greatest frequency, the following reasons were offered: cost of treatment, clinical inefficiencies leading to patient attrition, and competition with residents for clinical cases. Comments included the following: "We were promised patients in our second year, and so far, patient experience has been minimal. I mostly assist every clinic session"; "We were told that we would be seeing patients at the beginning of our second year, so many of our classes were added into first year or condensed. Now, because we don't have a big enough patient pool, we aren't seeing our patients. Everything we learned first year is kind of shaky because we haven't been using those skills"; "Fees for service provided at our school are high"; "We lack patients at this school"; "I lose patients because the cost of treatment is too high and the clinics are full of red tape"; and "The graduate programs take cases away from us because they have to learn too."

\section{Redundant and Irrelevant Curricular Content}

Finally, 9 percent of students' comments in the SWOT data described their perception of redundant and irrelevant curricular content. Comments regarding redundant content were most prevalent in the second year, whereas comments regarding irrelevant curricular content were most frequent in the fourth year. Eighteen percent of student comments in the focus groups centered on irrelevant content, indicating their perceived disconnect between the dental school curriculum and their anticipated needs for future clinical practice. Students most frequently suggested that lack of communication among faculty members, both intra- and interdepartment, was the reason for this disconnect. Comments included these: "Clinical Skills [course] was a repeat of everything we have learned already"; "Poor communication between various instructors: we have literally reviewed the same, exact lecture on multiple occasions throughout D1 and D2 [first and second] years."; "Many courses go over material already learned. ... A lot of material seems to be repeated"; "Faculty are not on the same page"; "There is no communication between departments"; "Basic sciences courses are filled with stuff we are not going to use as dentists"; and "The odds of me using the bulk of the material in our basic sciences in clinical application is pretty slim to none."

\section{Discussion}

This study gathered student feedback on recent curricular changes at our institution from the perspective of one dental school class going through all four years of the curriculum. Data were collected through administration of a SWOT questionnaire and focus groups to enable us to evaluate program goals including earlier patient care experiences, condensing preclinical curriculum, and developing a studentfriendly school environment. Annual administration of the SWOT questionnaire had the benefit of capturing students' most recent impressions, minimizing recall bias, for identification of curricular strengths and weaknesses by academic year. To build upon the questionnaire, focus groups were conducted in students' fourth year to confirm this data analysis and provide an opportunity for students to reflect on their overall experience during the course of the four-year curriculum. The five general themes identified serve as a framework for future curricular enhancements.

Most of the student comments related to the theme of preclinical lab and early clinical experiences. Consistent with the work of Henzi et al., our students expressed a strong desire for clinical exposure and patient interaction. ${ }^{10}$ They were generally pleased with their experiences in this regard. The impressions of the fourth-year students were that enhancements to the curriculum should focus on better defining the role of second-year students in the clinics and giving them more training on the school's electronic health care database so they could become more engaged in patient care. The fourth-year students noted that most of their own time in the clinic during their second year was of a supportive nature and did not involve direct patient care. Nevertheless, they perceived this involvement as beneficial since it gave them a chance to interact with patients and become familiar with clinical operations and protocols. An original intent of our curricular revision was to have second-year students directly involved with 
patient care as appropriate for their level of training. The reasons for this not occurring on a regular basis seem to be related to challenges with implementing the vertically integrated clinic system and probable patient recruitment and retention concerns (addressed later in this section). Schoolwide efforts are currently focused on addressing these clinic education issues. Efforts to enhance the vertically integrated system include setting and promoting clear expectations for second-year students' role in the clinic for both students and faculty. A checklist has been developed that articulates specific duties based on students' level of skill development and ties these duties to course expectations. Checklist duties include (but are not limited to) taking vital signs, documenting clinical findings in the electronic health record, administrating local anesthesia, preparing restorative or impression materials, and giving oral hygiene and postoperative instructions.

Data from the SWOT questionnaire administered indicated that the students in the first and second years perceived the condensed curriculum to be too fast-paced. However, when those students had reached the fourth year and reflected on this topic in focus groups, they did not feel that the pace was too hectic and thought that without the content covered they would not have been prepared for their third and fourth years. The difference in opinions from one time point to another could have been due to systematic cognition (the tendency to believe that the present self is better than the past self ${ }^{14,15}$ ) or fourth-year student selection biases. Nevertheless, immediate changes were made to adjust course schedules to more equally distribute the most rigorous courses. A next step is to better align course content to promote the development of intellectual skills according to Bloom's taxonomy of learning domains, in which knowledge is the most fundamental category and evaluation of ideas is the most advanced..$^{16}$ All together, these changes have the potential to maximize the quality of the educational experience associated with the original goal of condensing the early part of the curriculum.

Overall, it appears that the students were generally satisfied with the majority of dental school faculty members, describing them as knowledgeable, approachable, and invested in student learning. However, a notable number of these student comments seemed focused on a small number of faculty members whose teaching skills and attitudes were not thought to be aligned with a positive learning environment. ${ }^{17,18}$ Student comments about faculty members' uncooperativeness and difficulty to work with are consistent with Henzi et al.'s report on dental students' perceptions of their clinical education. ${ }^{19}$ An original goal of our curricular modification was to create a student-friendly environment by, in part, providing early clinical experiences, but building such an environment is highly dependent on faculty interactions with students. It is unlikely that these identified faculty deficiencies are a result of our curricular modification. However, our findings suggest a need for faculty development and formal setting of expectations with an emphasis on teaching methodologies, management skills, and professional academic responsibilities.

A perceived lack of dental school patients was another challenge identified in this study. Although it is difficult to tell if our overall patient numbers are an issue, internal records do show a decline in the number of endodontic and fixed prosthodontic procedures being performed by our students over the last ten years. Quality assurance data substantiates student perceptions that patients drop out of our system primarily due to the cost of treatment and/ or inefficient clinic operations. Since there is no internal system for monitoring patients referred to our advanced education clinics, building a case in support of student opinions that patients are being overly referred to resident clinics is difficult. As our curricular revisions did not directly involve or impact courses in endodontics or prosthodontics, it seems reasonable to conclude that curricular revisions did not contribute to students' perceived lack of readiness for entry-level practice in those areas. It may be that current student attitudes are a consequence of too few clinical experiences to obtain confidence in their own skill development. Other authors have reported that confidence level among dental students was lowest in areas where clinical opportunities to deliver care were infrequent. ${ }^{20,21}$ Having fewer clinical experiences impedes our students' skill development and readiness for independent clinical practice. Greater emphasis on building partnerships with communitybased clinics, marketing of dental services, and efficient clinic protocols are ways we are seeking to improve patient recruitment and retention.

Data analysis from both the SWOT questionnaire and focus groups also revealed comments on curricular redundancies and irrelevant content. Comments on redundant content were most frequent in the first and second years. It may be that poor communication among faculty members is to blame for repeating lectures and topics within the curriculum, as students suggested. Immediate action was taken to 
eliminate these occurrences by having faculty work together to identify repetitive topic areas. Subsequent student feedback from those courses directly involved has improved.

Our students also commented that they did not see the connection between basic science courses and future practice. This is consistent with Henzi et al.'s study, in which students from twenty dental schools questioned the relevance of biomedical, behavioral, and social science courses. ${ }^{10}$ Thus, our students' perception of a disconnect between the basic sciences and clinical practice is not unique, nor was it likely a direct result of our curricular revisions. Nevertheless, enhancements need to be made. A good place to begin is to bring the basic and clinical science faculty together to build educational opportunities that demonstrate the relationship between their respective fields. ${ }^{1,2,4,6}$ Such opportunities could build on the current activities already in place within the curriculum. More specifically, clinical faculty members visiting the gross anatomy lab could further highlight the anatomical landmarks involved with administration of local anesthesia, radiographic interpretation, and denture boarder molding through the use of small-group, hands-on demonstrations. A demonstration could include the identification and tagging of multiple boney landmarks both physically (on the cadaver) and radiographically. Additionally, biomedical science faculty members could work with students prior to their presentations to classmates, facilitating the identification of key associations such as the relationship between inflammatory processes and periodontal disease, liver function and postoperative hemostasis, and connective tissue disorders and wound healing.

\section{Limitations}

As with any qualitative study, our data analysis is subject to interpretation bias. Being aware of this, we incorporated a number of strategies into this investigation to reduce the likelihood of misrepresentation of student comments. First, data analysis was guided by one author (APW) who is well versed in qualitative analysis and health science education but unfamiliar with our curricular revisions. Second, multiple authors worked to develop the coding structures used, and intercoder reliability was high in application of the coding to data. Finally, focus groups and internal records were used to substantiate student opinions.
Selection bias is another potential influencing factor as the exact opinions of the nonparticipating students remain unknown. The response rates for the four questionnaire administrations ranged from 76 to 51 percent, with the lowest percentage ( 51 percent) occurring in the fourth year. Sixteen percent of fourth-year students participated in the focus groups. Recruitment efforts for both study methods consisted of three calls for participation via e-mail, providing a complimentary lunch, and scheduling during times deemed most convenient through consultation with class officers. Fourth-year students may have chosen not to complete the questionnaire or participate in the focus group for a variety of reasons such as fatigue with offering opinion as part of this study, feeling participation was irrelevant for them as no significant curricular changes would be implemented for this class in the months leading up to graduation, and being preoccupied with matters of completing patient cases, regional dental boards, and employment. Although greater participation was desirable and attempted, no new appreciable themes emerged from our qualitative data analysis, suggesting an adequate sample size existed..$^{22,23}$

Another limitation of this study was the relatively small number of comments expressed as opportunities and threats by students completing the SWOT questionnaire. Only fifty comments (5 percent of SWOT data captured) were considered true opportunities and threats and were not redundant with strengths and weaknesses. We believe that this lack of meaningful data resulted from students' misinterpreting or not understanding the questions posed. As the first two questions on the SWOT questionnaire asked students to comment on the strengths and weaknesses of their dental education so far, students likely thought they were to express opportunities and threats limited to their own experiences instead of commenting on those influencing the quality of dental education for future students. No modifications to the study protocol or instructions were made after this four-year study began. We anticipated that true opportunities and threats to the quality of dental education would be expressed as the students moved along in their education. Although the frequency of true opportunities and threats did increase throughout the duration of the study, they remained a very small subset of the overall data. Future studies aimed at obtaining student opinion about opportunities for improvement and threats to the quality of dental education may benefit from defining these terms. 
There are inherent limitations with the use of focus groups. Some participants may influence the perspectives expressed by others, particularly if a participant or multiple participants are very vocal or opinionated about a particular subject. An opinionated participant may also intimidate others and reduce the chance of different perspectives being heard. Focus group participants did not completely represent all races, ethnicities, or levels of academic performance in the fourth-year class, which may have influenced group discussions. Leading questions by the focus group facilitator could also lead to the biasing of results. Attempts to minimize biasing during focus group discussions were selecting a "neutral" and nonthreatening facilitator, creating a respectful environment, encouraging equal student participation in discussions, and mapping out a series of semi-structured interview questions meant to elicit feedback on SWOT analysis and interpretation but not leading the responses in a specific direction.

One overriding limitation of this study was that it captured student attitudes of curricular revisions from only one dental school class who experienced only one version of our curriculum. As such, it is difficult to generalize our results to other schools or other curricular revisions at our school. Student impressions documented here could have been influenced by our revisions or may have surfaced regardless. The experience of this class was followed closely by both students from other classes and faculty members as it was the first to go through the entire, phased-in, revised curriculum. The nature or their frequency of comments may thus have been influenced by student opinion from other classes and faculty eager for student feedback.

\section{Conclusions}

In this study, the general impressions of students as major stakeholders in curricular revision were captured and analyzed by qualitative methodology. It appears that the students were satisfied with aspects of their overall experience in the revised curriculum related to the preset goals, based on ADEA CCI best practices. ${ }^{2-7}$ These goals were earlier patient care experiences, condensing the preclinical curriculum, and developing a student-friendly school environment. Further research to triangulate student comments with other evaluation indicators such as faculty perceptions and student learning outcomes are necessary to clearly define strategies for further curricular improvements. The analysis reported here was based on student opinion from one dental school class experiencing one curricular version; therefore, broad generalizations cannot be made. However, our aim was to deeply understand our situation and to share that perspective with others facing similar situations. Thus, we wish to make the following recommendations for dental schools considering curricular revisions:

- Maximize early patient care experiences. Students appreciate these opportunities and value interacting with patients, exposure to clinic operations, and peer mentoring.

- Set clear expectations for student learning. Expectations should be based on students' progression of skill development and be well communicated to students and faculty.

- Carefully balance course load between semesters and academic years. Students will respond favorably to a well-planned and well-sequenced curriculum as they expect to work hard in preparing for patient care and future clinical practice.

- Integrate basic, social, and clinical sciences. Consider designing frequent learning opportunities in which diverse faculty groups with various expertise come together to share information and facilitate student learning.

In addition to these recommendations, we offer the opinion that curricular revision needs to be accompanied by faculty development and timely evaluation. The same thoughtful planning that goes into changing the curriculum needs to go into preparing faculty members to teach and function within it. Timely analysis of curricular evaluation data should be used to identify areas of success and those needing improvement, in order to continually motivate students and faculty to accept and further engage in curricular reform.

\section{REFERENCES}

1. Fields MJ, Jeffcoat MJ. Dental education at the crossroads: a report by the Institute of Medicine. J Am Dent Assoc 1995;126:191-5.

2. Kalkwarf KL, Haden NK, Valachovic RW. ADEA Commission on Change and Innovation in Dental Education. J Dent Educ 2005;69(9):1085-7.

3. Pyle M, Andrieu SC, Chadwick DG, Chmar JE, Cole JR, George MC, et al. The case for change in dental education. J Dent Educ 2006;70(9):921-4.

4. Anderson MH. Dentistry and dental education in the context of the evolving health care system. J Dent Educ 2007;71(8):988-93. 
5. Haden NK, Andrieu SC, Chadwick DG, Chmar JE, Cole JR, George MC, et al. The dental education environment. J Dent Educ 2006;70(12):1265-70.

6. DePaola DP. The revitalization of U.S. dental education. J Dent Educ 2008;72(2 Suppl):28-42.

7. Crain G. Managing change in dental education: is there a method to the madness? J Dent Educ 2008;72(10):1100 13.

8. Learned E, Christensen C, Andrews K, Guth W. Business policy. Homewood: Irwin, 1969.

9. Gordon J, Hazlett C, Ten Cate O, Mann K, Kilminster S, Prince K, et al. Strategic planning in medical education: enhancing the learning environment for students in clinical settings. Med Educ 2000;34(10):841-50.

10. Henzi D, Davis E, Jasinevicius R, Hendricson WD. In the students' own words: what are the strengths and weaknesses of the dental school curriculum? J Dent Educ 2007;71(5):632-45.

11. Bogdan RC, Biklen SK. Qualitative research for education: an introduction to theories and methods. Boston: Pearson, 2007.

12. Denzin NK, Lincoln YS. The Sage handbook of qualitative research. 3rd ed. Thousand Oaks, CA: Sage Publications, 2005.

13. Bryman AS, Burgess R. Analyzing qualitative data. London: Routledge, 1994.

14. Hill LG, Betz DL. Revisiting the retrospective pretest. Am J Evaluation 2005;26(4):501-17.
15. Lam TCM, Bengo P. A comparison of three retrospective self-reporting methods of measuring change in instructional practice. Am J Evaluation 2003;24(1):65-80.

16. Bloom B, Englehart M, Furst E, Hill W, Krathwohl D. Taxonomy of educational objectives: the classification of educational goals. Handbook I: cognitive domain. New York: Longmans, Green, 1956.

17. Al-Hazimi A, Al-Hyiani A, Roff S. Perceptions of the educational environment of the medical school in King Abdul Aziz University, Saudi Arabia. Med Teach 2004;26(6):570-3.

18. Stark P. Teaching and learning in the clinical setting: a qualitative study of the perceptions of students and teachers. Med Educ 2003;37(11):975-82.

19. Henzi D, Davis E, Jasinevicius R, Hendricson W. North American dental students' perspectives about their clinical education. J Dent Educ 2006;70(4):361-77.

20. Honey J, Lynch CD, Burke FM, Gilmour AS. Ready for practice? A study of confidence levels of final-year dental students at Cardiff University and University College Cork. Eur J Dent Educ 2011;15(2):98-103.

21. Holmes DC, Diaz-Arnold AM, Williams VD. Alumni self-perception of competence at time of dental school graduation. J Dent Educ 1997;61(6):465-72.

22. Patton MQ. Qualitative evaluation and research methods. Thousand Oaks, CA: Sage Publications, 2002.

23. Kruger RA, Casey MA. Focus groups: a practical guide for applied research. Thousand Oaks, CA: Sage Publications, 2009. 